\title{
Jaundice after repeated exposure to halothane: a further analysis of reports to the Committee on Safety of Medicines
}

\author{
WILLIAM H W INMAN, WILLIAM W MUSHIN
}

British Medical fournal, 1978, 2, 1455-1456

\section{Summary and conclusions}

Analysis of data derived from 170 reports of jaundice developing after anaesthesia with halothane received after January 1974 confirmed the relations between multiple exposure to halothane and jaundice and between the number of exposures and the rapidity with which jaundice develops after exposure. When these reports were combined with 130 received earlier complete anaesthetic histories were available for 251 patients, $205(82 \%)$ of whom had been exposed to halothane more than once; of these patients, $154(75 \%)$ had been exposed more than once within 28 days. Altogether $139(46 \%)$ of the 300 patients died.

\section{Introduction}

In 1974 we published the results of an analysis of 130 reports of jaundice sent to the Committee on Safety of Medicines over 10 years, ${ }^{1}$ which showed a pronounced reduction in the interval between exposure to halothane and the onset of jaundice in patients who had received two or more exposures when compared with those receiving only a single exposure. This was especially true of the patients exposed several times within a short period. We concluded that although factors other than exposure to halothane could account for some of the reports, it would be wise, when planning a series of anaesthetics, to reserve halothane "for the one operation where its advantages may be greatest." We now present an analysis of cases notified to the Committee on Safety of Medicines after the earlier report.

\section{Patients and methods}

In the interval between preparing our previous report ${ }^{1}$ and its publication we received 77 reports of postoperative jaundice. After publication we received a further 93 reports, which brought the total to 170 . Of these, 33 gave only incomplete anaesthetic histories and were not considered further. Thus 137 new cases were available for analysis.

\section{Results}

Table I shows the principal results. Adequate anaesthetic histories were available in 251 cases (including those for 114 cases reported previously $\left.{ }^{1}\right)$. Two hundred and five of the patients had been exposed to halothane more than once, and of these, $154(75 \%)$ had been exposed more than once within 28 days. The mean interval between the last exposure to halothane and the onset of jaundice in those exposed more than once was considerably shorter than that in patients given a single halothane anaesthetic. This effect was even more

Committee on Safety of Medicines, London EC2A 1PP

WILLIAM $\mathrm{H}$ W INMAN, MRCP, FFCM, principal medical officer

Welsh National School of Medicine, Cardiff

WILLIAM W MUSHIN, FRCS, FFARCS, emeritus professor of anaesthetics

pronounced in those patients in whom the interval between the penultimate and the last exposure to halothane was under 28 days (see table II). One hundred and twenty-two patients $(49 \%)$ died. Mortality was $35 \%$ in those exposed on only one occasion compared with $51-52 \%$ in those exposed twice or more. There was a correlation with age, which is seen more clearly in a separate analysis ignoring the number of halothane anaesthetics (table III).

TABLE I-Details taken from reports of jaundice in patients exposed to halothane. Figures in parentheses are from first series ${ }^{1}$

\begin{tabular}{|c|c|c|c|c|c|}
\hline $\begin{array}{c}\text { No of } \\
\text { exposures }\end{array}$ & $\begin{array}{l}\text { No of } \\
\text { cases of } \\
\text { jaundice }\end{array}$ & $\begin{array}{c}\text { Mean } \\
\text { age } \\
\text { (years) }\end{array}$ & $\begin{array}{l}\% \text { of } \\
\text { patients } \\
\text { exposed } \\
\text { twice or } \\
\text { more within } \\
28 \text { days }\end{array}$ & $\begin{array}{c}\text { Mean } \\
\text { interval } \\
\text { between } \\
\text { last exposure } \\
\text { and onset of } \\
\text { jaundice } \\
\text { (days) }\end{array}$ & $\begin{array}{c}\% \text { of } \\
\text { patients } \\
\text { dying } \\
\text { (deaths } \\
\text { attributed } \\
\text { to jaundice) }\end{array}$ \\
\hline $\begin{array}{l}1 \\
2 \\
3 \\
4\end{array}$ & $\begin{array}{r}46(20) \\
109(49) \\
63(29) \\
33(16)\end{array}$ & $\begin{array}{l}50 \cdot 9 \\
57 \cdot 9 \\
55 \cdot 2 \\
62 \cdot 3\end{array}$ & $\begin{array}{l}72(80) \\
80(86) \\
78(79)\end{array}$ & $\begin{array}{c}11 \cdot 4(11 \cdot 7) \\
5 \cdot 8(6 \cdot 7) \\
5 \cdot 1(4 \cdot 6) \\
4 \cdot 1(5 \cdot 3)\end{array}$ & $\begin{array}{l}35(35) \\
51(53) \\
52(59) \\
52(63)\end{array}$ \\
\hline All cases & $251(114)$ & 56.5 & 75 & $6.4(6.8)$ & $49(53)$ \\
\hline
\end{tabular}

TABLE II-Relation between interval between two most recent exposures and day of onset of jaundice

\begin{tabular}{c|c|c}
\hline \multirow{4}{*}{$\begin{array}{c}\text { Total No } \\
\text { of exposures }\end{array}$} & \multicolumn{2}{|c}{$\begin{array}{c}\text { Mean interval between onset of jaundice and last } \\
\text { exposure (days) }\end{array}$} \\
\cline { 2 - 3 } & $\begin{array}{c}\text { More than 28 days } \\
\text { between penultimate and } \\
\text { last exposure }\end{array}$ & $\begin{array}{c}\text { Under 28 days between } \\
\text { penultimate and last } \\
\text { exposure }\end{array}$ \\
\hline 2 & $\begin{array}{c}10 \cdot 5(\mathrm{n}=19) \\
7 \cdot 4(\mathrm{n}=11)\end{array}$ & $\begin{array}{c}5 \cdot 6(\mathrm{n}=67) \\
4 \cdot 6(\mathrm{n}=40) \\
3 \cdot 5(\mathrm{n}=8)\end{array}$ \\
\hline 4 & $8 \cdot 4(\mathrm{n}=17)$ \\
\hline All cases & $5 \cdot 0(\mathrm{n}=38)$ & $524)$ \\
\hline
\end{tabular}

TABLE III-Proportion of fatal cases in each age group

\begin{tabular}{l|c|c|c|c|c|c|c|c|c|c}
\hline \multicolumn{1}{c|}{ Age in years: } & $0-$ & $10-$ & $20-$ & $\frac{30-}{40}$ & $\frac{40-}{50-}$ & $\frac{60-}{70-}$ & $\begin{array}{c}\text { Not } \\
\text { known }\end{array}$ & $\begin{array}{c}\text { All } \\
\text { ages }\end{array}$ \\
\hline $\begin{array}{l}\text { No of cases } \\
\text { No of fatal cases }\end{array}$ & 1 & 3 & 10 & 17 & 41 & 58 & 73 & 37 & 11 & 251 \\
2 & 8 & 17 & 24 & 38 & 27 & 5 & 122
\end{tabular}

\section{Discussion}

Much controversy has surrounded the role of halothane in liver damage, particularly after our earlier study. Nevertheless, several reports have supported our conclusions, prominent among these being one from Walton $e t a l,{ }^{2}$ which gave details of 203 patients who had been examined by a panel of hepatologists. Out of 76 patients in whom no identifiable cause of jaundice was found, $72(95 \%)$ had been given several halothane anaesthetics, and $42(55 \%)$ had undergone repeated exposure within four weeks. Only 13 patients had died, suggesting that many of these cases were milder than those reported to the Committee on Safety of Medicines. The authors concluded that their analysis "now supports the findings of Inman and Mushin." It was not possible to determine the degree of overlap between that series and our own, but part of the similarity between the results could be accounted for by reporting to 
both groups. Our reports had been followed up by the medical secretariat and field workers, none of whom was a practising anaesthetist or hepatologist. The series of Walton et al was followed up by anaesthetists and the material submitted to a panel of experts. Despite these differences, both groups of workers came to the same conclusions. Neither study enabled the true incidence of post-halothane jaundice to be measured, nor was it possible to show a similar risk of damage to hepatic function associated with multiple exposures to non-halothane anaesthetics, but both suggested an additional hazard after multiple exposure to halothane.

In our previous report we overlooked an important article ${ }^{3}$ in which 60 cases of post-halothane jaundice, including 11 deaths, were analysed. Forty-one $(69 \%)$ of all the patients and 10 of the 11 who died had been given two or more anaesthetics, and the authors proposed that an interval of at least two weeks between exposures to halothane was desirable. In another Swedish paper Dalsgaard et $a^{4}$ described 11 cases in which the patients had received two or more halothane anaesthetics. Five of the patients died. The mean onset of jaundice was 4.5 days. Other reports include that of Joshi and Conn, ${ }^{5}$ who reviewed 24 cases of postoperative jaundice developing after methoxyflurane, in which 12 of the patients had previously been exposed to this agent or halothane. Jaundice had developed on average 5.8 days after the anaesthetic, but the mean latent period was only 3.4 days in the 12 who had had previous exposures to one of these agents. The authors suggested that "this shortening of the latent period with serial exposures is strong evidence of drug-sensitising injury." Their work suggested that the two agents may cross-sensitise. Wright $e t a l^{6}$ and Trowell et al found ncreases in transaminase concentrations to be more common in patients anaesthetised with halothane than in those receiving other agents.

The publicity and controversy surrounding our earlier report might have been expected to influence not only the subsequent reporting but also the type of case reported. Those who agreed with our earlier conclusions might have been more likely to support us by reporting similar cases, particularly if jaundice had occurred after repeated exposures to halothane.
Conversely, it might have been reasonable to expect a general reduction in the number of such cases because anaesthetists might begin to use other agents in patients needing repeated procedures. In practice, however, the pattern of reports since the beginning of 1974 was similar to that seen in our earlier series. The number of cases reported probably bears little relation to the number that actually occur. Walton et al accumulated more than 200 reports over three years, while the Committee on Safety of Medicines took 10 years to accumulate the 130 reports that we analysed in 1974. When allowance is made for cases reported retrospectively after our earlier analysis, it may be seen that 207 of the patients in the reported cases developed jaundice during 1964-73 and a further 93 cases were reported during 1974-7. The average number of cases reported each year was similar, and no change was apparent as a result of our report.

We conclude by reaffirming our view that, in the light of the evidence that repeated exposure to halothane within a short period increases the risk of jaundice, anaesthetists should carefully consider the circumstances of each patient before deciding to use halothane.

We wish to express our thanks to the Committee on Safety of Medicines and its Chairman, Professor Sir Eric Scowen, for permission to use these data.

Requests for reprints should be addressed to Dr W H W Inman, Committee on Safety of Medicines, Finsbury Square House, 33/37A Finsbury Square, London EC2A 1PP.

\section{References}

${ }^{1}$ Inman, W H W, and Mushin, W W, British Medical fournal, 1974, 1, 5. Walton, B, et al, British Medical fournal, 1976, 1, 1171

Böttiger, L E, Dalen, E, and Hallen, B, Läkartidningen, 1973, 70, 4291 Dalsgaard, M, Andreasen, P B, and Ranek, L, Ugeskrift for Laeger, 1974, 136, 132.

Joshi, P H, and Conn, H O, Annals of Internal Medicine, 1974, 80, 395.

Wright, R, et al, Lancet, 1975, 1, 817.

Trowell, J, Peto, R, and Crampton Smith, A, Lancet, 1975, 1, 821.

(Accepted 3 October 1978)
ONE HUNDRED YEARS AGO Dr Berger has had the opportunity of studying 105 cases of epilepsy, which have partly come under his own observation and partly been collected by others; and gives the following statements on the frequency and etiology of the disease. In 65.93 per cent of the cases, the disease first showed itself in the time between infancy and the twentieth year; but much more frequently than has been accepted hitherto during the first four years of childhood. The female sex is particularly exposed to it at the age of fifteen to twenty, and the male sex in the years between thirty and forty. This difference may be explained by the beginning of puberty in women and by the excesses committed by men at that time. The cessation of the menses has not the least influence on epilepsy, which very seldom appears for the first time in old age. Dr Berger observed it once in an old woman aged seventy-four, in whom, after having been perfectly well all her life, the first attack of this disease was produced by a very violent fright. Epilepsy is often hereditary, as the author has distinctly traced in 23 cases out of 71 which he had studied for the purpose of elucidating the question. He has never observed the first outbreak of the disease occur either before the beginning of puberty or after the thirtieth year. In both sexes, and especially in women, epilepsia gravior is the most common form. The author gives a series of observations on the etiology of epilepsy, which tend to illustrate the different experiments that have been made to produce epilepsy artificially. The following were the principal causes. A traumatic affection of the median nerve caused enilepsy in a man; disturbances of the sexual organs in women had the same effect. (One was a case of haemelytrometra, which was subsequently operated on; the other, cessation of the menses caused by a severe cold.) Four cases may be classed under the head of epilepsy caused by injury. The patients (three male, one female) had sustained injuries to the head, either through a blow, fall, or box on the ear, and the disease subsequently manifested itself either directly afterwards, or after weeks or even months had elapsed, while in the meantime the only thing the patients complained of occasionally were diffused headaches. The next cases belong to the form of epilepsy caused by affection of the cortical substance, especially in syphilitic persons (according to Fournier, Charcot, and others). Among these, he gives a very full description of a case of epilepsy in a man aged thirty-eight, who had been several times under treatment for syphilis, and who was subject to epileptiform attacks that did not differ in the least from general epilepsy. He was cured by a very energetic antisyphilitic treatment. Two further cases recorded describe vaso-motor epilepsy in a girl aged nineteen, and a very interesting case of epilepsia gravior occurring also in a girl aged nineteen after poisoning with carbonic acid. In the treatment of the disease, the author has used several methods with varying success. Hystero-epileptic patients were the only ones that derived any benefit from Chapman's method of application of ice or cold water to different parts of the body; true epilepsy was never cured either by this method or by electricity. In vaso-motor epilepsy, the constant current proved very useful. Some authors have highly commended the effects of bromide of camphor and bromate of zinc; but $\mathrm{Dr}$ Berger does not agree with them; neither has he seen any satisfactory results produced by atronin and curare; nitrite of amyl, if inhaled in time, sometimes proved efficient in cutting short the paroxysm. The most favourable result has been caused by bromide of potassium, if given in large doses (from six to twelve grammes, equal to one and a half to three drachms, daily); the disease sometimes only manifested itself again after two years, but it never was completely cured. Bromal-hydrate has a similar effect to that of bromide of potassium. (British Medical fournal, 1878.) 